\title{
Equivalencing the Collector System of a Large Wind Power Plant
}

\section{Preprint}

E. Muljadi and C.P. Butterfield

National Renewable Energy Laboratory

A. Ellis and $\mathrm{J}$. Mechenbier

Public Service Company of New Mexico

J. Hochheimer and R. Young FPL Energy LLC

N. Miller and R. Delmerico

General Electric International, Inc.

R. Zavadil and J.C. Smith Utility Wind Interest Group

To be presented at the 2006 IEEE Power Engineering Society General Meeting

Montreal, Quebec, Canada

June 18-22, 2006

Conference Paper NREL/CP-500-38940

January 2006 


\section{NOTICE}

The submitted manuscript has been offered by an employee of the Midwest Research Institute (MRI), a contractor of the US Government under Contract No. DE-AC36-99G010337. Accordingly, the US Government and MRI retain a nonexclusive royalty-free license to publish or reproduce the published form of this contribution, or allow others to do so, for US Government purposes.

This report was prepared as an account of work sponsored by an agency of the United States government. Neither the United States government nor any agency thereof, nor any of their employees, makes any warranty, express or implied, or assumes any legal liability or responsibility for the accuracy, completeness, or usefulness of any information, apparatus, product, or process disclosed, or represents that its use would not infringe privately owned rights. Reference herein to any specific commercial product, process, or service by trade name, trademark, manufacturer, or otherwise does not necessarily constitute or imply its endorsement, recommendation, or favoring by the United States government or any agency thereof. The views and opinions of authors expressed herein do not necessarily state or reflect those of the United States government or any agency thereof.

Available electronically at http://www.osti.gov/bridge

Available for a processing fee to U.S. Department of Energy and its contractors, in paper, from:

U.S. Department of Energy

Office of Scientific and Technical Information

P.O. Box 62

Oak Ridge, TN 37831-0062

phone: 865.576.8401

fax: 865.576 .5728

email: mailto:reports@adonis.osti.gov

Available for sale to the public, in paper, from:

U.S. Department of Commerce

National Technical Information Service

5285 Port Royal Road

Springfield, VA 22161

phone: 800.553 .6847

fax: 703.605.6900

email: orders@ntis.fedworld.gov

online ordering: http://www.ntis.gov/ordering.htm 


\section{EQUIVALENCING THE COLLECTOR SYSTEM OF A LARGE WIND POWER PLANT}

\author{
E. Muljadi C.P. Butterfield \\ National Renewable Energy Laboratory \\ 1617 Cole Blvd \\ Golden, CO 80401
}

\author{
A. Ellis J. Mechenbier \\ Public Service Company of New Mexico \\ Alvarado Square, MS 0604 \\ Albuquerque NM 87158
}

\author{
J. Hochheimer R. Young \\ FPL Energy LLC \\ 700 Universe Blvd. \\ Juno Beach, FL 33408
}

\author{
N. Miller R.Delmerico \\ General Electric International, Inc. \\ 1 River Road, Bldg. 2-605 \\ Schenectady, New York 12345
}

\author{
R. Zavadil J.C.Smith \\ Utility Wind Interest Group \\ 2004 Lakebreeze Way \\ Reston, VA 20191
}

\begin{abstract}
As the size and number of wind power plants (also called wind farms) increases, power system planners will need to study their impact on the power system in more detail. As the level of wind power penetration into the grid increases, the transmission system integration requirements will become more critical [1-2].
\end{abstract}

A very large wind power plant may contain hundreds of megawatt-size wind turbines. These turbines are interconnected by an intricate collector system. While the impact of individual turbines on the larger power system network is minimal, collectively, wind turbines can have a significant impact on the power systems during a severe disturbance such as a nearby fault. Since it is not practical to represent all individual wind turbines to conduct simulations, a simplified equivalent representation is required.

This paper focuses on our effort to develop an equivalent representation of a wind power plant collector system for power system planning studies. The layout of the wind power plant, the size and type of conductors used, and the method of delivery (overhead or buried cables) all influence the performance of the collector system inside the wind power plant. Our effort to develop an equivalent representation of the collector system for wind power plants is an attempt to simplify power system modeling for future developments or planned expansions of wind power plants. Although we use a specific large wind power plant as a case study, the concept is applicable for any type of wind power plant.

Index Terms - wind turbine, wind farm, wind power plant, wind energy, aggregation, equivalence, distribution network, collector system, power systems, renewable energy.

\section{INTRODUCTION}

Although it is very important to understand the dynamics of individual turbines [3-4], the collective behavior of the wind power plant and the accuracy in modeling the collector systems are also very critical in assessing wind power plant characteristics. Among other aspects, the design of collector systems for wind power plants seeks to minimize losses and voltage drops within budgetary constraints. This philosophy is generally applied regardless of the size of the wind power plant, the types of the turbines and reactive power compensation.

Within a wind power plant, wind turbines are placed optimally to harvest as much wind energy as possible. The turbine layout in a large wind power plant on a flat terrain is different from the layout of a wind power plant located on mountain ridges. The different layouts will have different impacts on the line impedances to the grid interconnection bus.

This paper describes an analytical approach that can be used to derive the equivalent representation of a wind power plant collector system. Many textbooks on distribution system modeling are available [5], but this paper focuses on modeling wind power plant collector systems in particular. To illustrate the methodology, we used data from the New Mexico Wind Energy Center (NMWEC), which is interconnected to the transmission grid owned and operated by Public Service Company of New Mexico (PNM). To independently verify the calculation, we used two different concepts. The first concept is based on circuit analysis, and the second one is based on load flow analysis. Although we used the Positive Sequence Load Flow (PSLF ${ }^{\mathrm{TM}}$ ) program from General Electric for our process, other programs, such as Power Systems Simulation for Engineers (PSSE ${ }^{\mathrm{TM}}$ ) from Siemens Power Technologies Inc., can also be used.

Figure 1 shows a simplified one-line diagram for the single-machine equivalent of the NMWEC. Bus 10999 is the point of interconnection to the utility grid. Note 
that this node is represented as an infinite bus, such that it is not necessary to include any details about the system external to the wind power plant. The parameters that we seek to derive are highlighted

Section II describes the steps we used to derive the equivalent impedance of a power system network. Section III presents two types of simplification, and Section IV presents and tabulates the result of the calculation. Section V presents the load-flow calculation, and Section VI the result and summary.

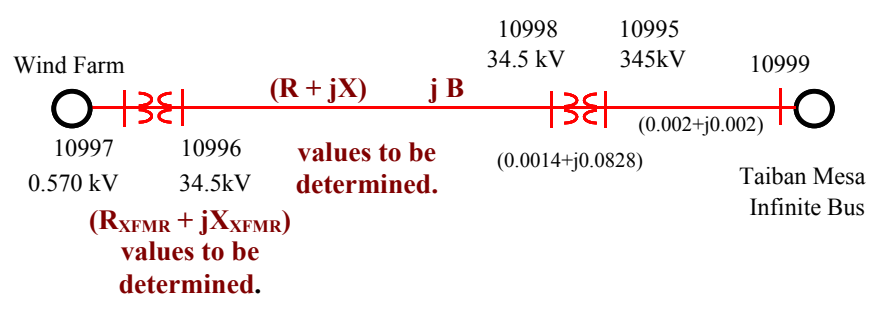

Figure 1. Simplified one-line diagram of a typical wind power plant connected to a substation.

The parameter that the developer provided for PNM planning study purposes are listed on last row of table 1 .

\section{STEP BY STEP DERIVATION}

\section{A. General overview and assumptions}

In this section, we describe the background of the circuit simplification. A modern utility-size wind turbine generates electrical power at a low voltage level (typically $575 \mathrm{~V}$ or $690 \mathrm{~V}$ ). Current utility-scale wind turbine ratings range from $1.5 \mathrm{MW}$ to $5 \mathrm{MW}$ per turbine. Each wind turbine is electrically attached to a pad mounted transformer that steps up the voltage to a medium voltage level, typically $34.5 \mathrm{kV}$.

At the $34.5 \mathrm{kV}$ level, wind turbines are connected to each other in a string or "daisy chain" configuration (Fig. 2). Underground cables are most commonly used as trunk lines. Three or more turbines may be connected in this way to trunk lines, which then connect to one of

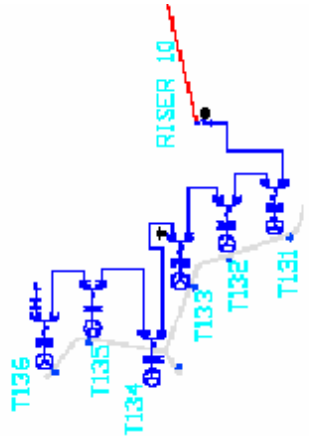

(a)

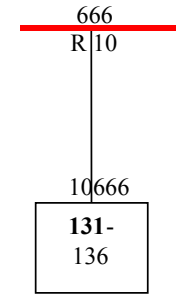

(b)
Figure 2 a) single series daisy-chain physical diagram b) equivalent representation of circuit (a) possibly several feeder circuits that use a larger conductor. The feeder circuits can be underground cables or overhead lines. These feeders connect to a $34.5 \mathrm{kV}$ bus that is connected to the wind power plant's substation transformer. The substation transformer steps up the voltage from a sub-transmission voltage level to a transmission voltage level ( $60 \mathrm{kV}$ or above).

In the following derivation, we based our equivalent circuit on apparent power losses (real power losses and reactive power losses). We made the following assumptions to derive the general equation for a circuit within a wind power plant:

- The current injection from all wind turbines is assumed to be identical in magnitude and angle.

- Reactive power generated by the line capacitive shunts is based on the assumption that the voltage at the buses is one per unit.

\section{B. Connection at the trunk line level}

The first step is to derive the equivalent circuit for two or more turbines connected in a daisy-chain configuration (Figure 2).

The equivalent circuit of the daisy-chain network shown in Figure 2 is represented in Figure 3. Note that the pad-mounted transformer is considered to be part of the generator itself. At this stage, we are only interested in the equivalent impedance of the collector system, excluding the pad-mounted transformers. Each of the currents shown is a phasor quantity, as follows:

$\mathbf{I}_{\mathbf{m}}=\mathrm{I}_{\mathrm{m}} / \theta_{\mathrm{m}}$

In this paper, a boldfaced variable indicates a phasor quantity. For instance, $\mathbf{I}_{\mathbf{1}}$ represents the current out of the wind turbine 1. The magnitude and angle of the phasor $\mathbf{I}_{\mathbf{1}}$ are $\mathrm{I}_{1}$ and $\theta_{1}$, respectively. Since current injections from each turbine are assumed to be identical, we obtain the following:

$I_{1}=I_{2}=I_{3}=I_{4}=I$

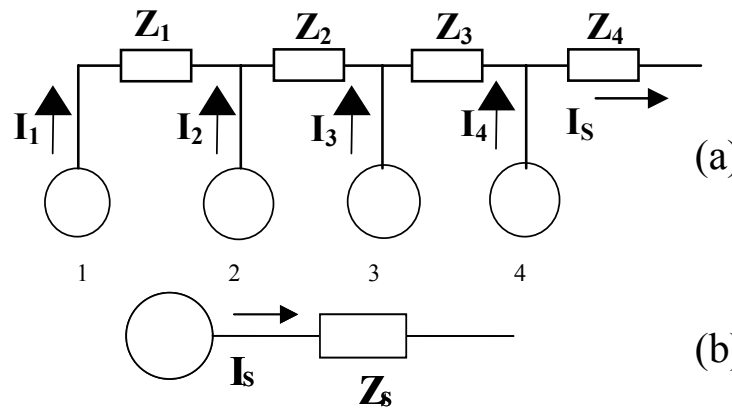

Figure 3 a) single series daisy-chain

b) equivalent representation of circuit (a) 
Therefore, the total current in the equivalent representation is given by:

$\mathbf{I}_{\mathbf{S}}=\mathrm{n} \mathbf{I}$

The voltage drop across each impedance, can be easily derived as follows.

The voltage drop across $\mathbf{Z}_{\mathbf{1}}=\Delta \mathbf{V}_{\mathbf{Z 1}}=\mathbf{I}_{\mathbf{1}} \mathbf{Z}_{\mathbf{1}}=\mathbf{I} \mathbf{Z}_{\mathbf{1}}$

The voltage drop across $\mathbf{Z}_{\mathbf{2}}=\Delta \mathbf{V}_{\mathbf{Z} 2}=\left(\mathbf{I}_{1}+\mathbf{I}_{2}\right) \mathbf{Z}_{\mathbf{2}}=\mathbf{2} \mathbf{I} \mathbf{Z}_{\mathbf{2}}$

The voltage drop across $\mathbf{Z}_{4}=$

$\Delta V_{Z 4}=\left(I_{1}+I_{2}+I_{3}+I_{4}\right) Z_{4}=4 I_{Z_{4}}$

The power loss at each impedance, can be computed as:

$S_{\text {Loss_Z1 }}=\Delta V_{Z 1} I_{1}{ }^{*}=I_{1} I_{1}{ }^{*} Z_{1}=I I^{*} Z_{1}=I^{2} Z_{1}$

$\mathbf{S}_{\text {Loss_Z2 }}=\Delta \mathbf{V}_{\mathbf{Z 2}}\left(\mathbf{I}_{1}+\mathbf{I}_{\mathbf{2}}\right)^{*}=2 \mathbf{I} \mathbf{Z}_{\mathbf{2}}(2 \mathbf{I})^{*}=2^{2} \mathrm{I}^{2} \mathbf{Z}_{\mathbf{2}}$

$\mathbf{S}_{\text {Loss_Z6 }}=\Delta \mathbf{V}_{\mathrm{Z6}}\left(\mathbf{I}_{1}+\mathbf{I}_{2}+\mathbf{I}_{3}+\mathbf{I}_{4}\right)^{*}$

$$
=4^{2} \mathrm{I}^{2} \mathbf{Z}_{4}
$$

Since $\mathbf{I}_{\mathbf{S}}=\mathrm{n} \mathbf{I}$, the power loss equation can be simplified as follows:

$\mathrm{S}_{\text {Tot_loss }}=\mathrm{I}^{2}\left(\mathrm{Z}_{1}+2^{2} \mathrm{Z}_{2}+3^{2} \mathrm{Z}_{3}+4^{2} \mathrm{Z}_{4}\right)$

$\mathrm{S}_{\text {Tot_loss }}=\mathrm{I}^{2} \sum_{m=1}^{n} \mathrm{~m}^{2} \mathrm{Z}_{\mathrm{m}}$

where

$I=$ output current of a single turbine

$m=$ index

$n=$ number of turbines in a string

The equations for the simplified circuit can be written as folllows:

$$
\begin{aligned}
& \mathrm{S}_{\text {Tot_loss }}=\mathrm{I}_{\mathrm{S}}{ }^{2} \mathrm{Z}_{\mathrm{S}} \\
& \mathrm{Z}_{\mathrm{S}}=\frac{\sum_{m=1}^{n} \mathrm{~m}^{2} \mathrm{Z}_{\mathrm{m}}}{\mathrm{n}^{2}}
\end{aligned}
$$

$\mathrm{Z}_{\mathrm{m}}$ represents the individual series impedances.

\section{Connection at the feeder level}

Consider parallel branches connected to the same nodes as shown in Figure 4. Each branch has a unique impedance and is connected to a group of wind turbines. Let us consider a simple three-branch configuration connected to the same node. For this configuration, we made the following assumptions:

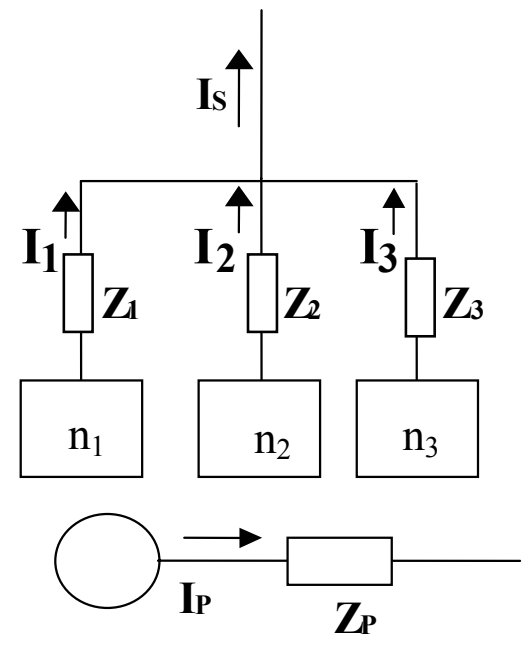

Figure 4. Parallel connection of three groups of turbines through series impedances $Z_{1}, Z_{2}$ and $Z_{3}$.

- Equivalent circuits for three circuits have been found following the methodology described in the previous section II.A.

- Originally, each trunk circuit equivalent consisted of $\mathrm{n}_{1}, \mathrm{n}_{2}$ and $\mathrm{n}_{3}$ turbines respectively

- All turbines are producing identical output in magnitude and phase angle.

- The impedance from each group to the point of interconnection is $\mathbf{Z}_{\mathbf{1}}, \mathbf{Z}_{\mathbf{2}}, \mathbf{Z}_{\mathbf{3}}$ respectively

The output currents from each group are given as follows:

$\mathbf{I}_{1}=\mathrm{n}_{1} \mathbf{I}$

$\mathbf{I}_{2}=\mathrm{n}_{2} \mathbf{I}$

$\mathbf{I}_{3}=\mathrm{n}_{3} \mathbf{I}$

The total output from the parallel branches are give as:

$$
\begin{aligned}
& \mathbf{I}_{\mathbf{P}}=\mathbf{I}_{\mathbf{1}}+\mathbf{I}_{\mathbf{2}}+\mathbf{I}_{\mathbf{3}} \\
& \mathbf{I}_{\mathbf{P}}=\mathrm{n}_{1} \mathbf{I}+\mathrm{n}_{2} \mathbf{I}+\mathrm{n}_{3} \mathbf{I} \\
& \mathrm{I}_{\mathrm{P}}=\left(\mathrm{n}_{1}+\mathrm{n}_{2}+\mathrm{n}_{3}\right) \mathrm{I}
\end{aligned}
$$

Losses in individual branches:

$$
\begin{aligned}
& \mathbf{S}_{\mathbf{Z 1}}=\mathrm{I}_{1}{ }^{2} \mathbf{Z}_{\mathbf{1}} \\
& \mathbf{S}_{\mathbf{Z} \mathbf{2}}=\mathrm{I}_{2}{ }^{2} \mathbf{Z}_{\mathbf{2}} \\
& \mathbf{S}_{\mathbf{Z} \mathbf{3}}=\mathrm{I}_{3}{ }^{2} \mathbf{Z}_{\mathbf{3}}
\end{aligned}
$$

The total loss is:

$$
\mathbf{S}_{\mathbf{Z P}}=\mathrm{I}_{\mathrm{P}}^{2} \mathbf{Z}_{\mathbf{P}}
$$

By substitution, we derived the following equations:

$$
\begin{aligned}
& \mathrm{I}_{\mathrm{P}}^{2} \mathbf{Z}_{\mathbf{P}}=\mathrm{I}_{1}^{2} \mathbf{Z}_{\mathbf{1}}+\mathrm{I}_{2}^{2} \mathbf{Z}_{\mathbf{2}}+\mathrm{I}_{3}^{2} \mathbf{Z}_{\mathbf{3}} \\
& =\mathrm{I}^{2} \mathrm{n}_{1}^{2} \mathbf{Z}_{\mathbf{1}}+\mathrm{I}^{2} \mathrm{n}_{2}^{2} \mathbf{Z}_{\mathbf{2}}+\mathrm{I}^{2} \mathrm{n}_{3}^{2} \mathbf{Z}_{\mathbf{3}} \\
& \mathbf{Z}_{\mathbf{P}}=\left(\mathrm{n}_{1}{ }^{2} \mathbf{Z}_{\mathbf{1}}+\mathrm{n}_{2}{ }^{2} \mathbf{Z}_{\mathbf{2}}+\mathrm{n}_{3}{ }^{2} \mathbf{Z}_{\mathbf{3}}\right) /\left(\mathrm{n}_{1}+\mathrm{n}_{2}+\mathrm{n}_{3}\right)^{2}
\end{aligned}
$$


The above equation can be further simplified:

$$
\mathrm{Z}_{\mathrm{P}}=\frac{\sum_{m=1}^{n} \mathrm{n}_{\mathrm{m}}^{2} \mathrm{Z}_{\mathrm{m}}}{\left[\sum_{m=1}^{n} \mathrm{n}_{\mathrm{m}}\right]^{2}}
$$

$\mathrm{Z}_{\mathrm{m}}$ represents the equivalent impedance of the individual parallel groups.

\section{Connection at the $34 \mathrm{kV}$ main bus}

Consider the series of parallel branches represented by Figure 5. The circuit shown in Figure 5 represents the parallel combination of several feeders at $34.5 \mathrm{kV}$.

For this configuration, we made the following assumptions:

- All turbines are producing identical output in magnitude and phase.

- Between two points of inter-connection, there are a series of impedances, $\mathbf{Z}_{1 \mathrm{~S}}, \mathbf{Z}_{\mathbf{2 S}}$, and $\mathbf{Z}_{\mathbf{3 S}}$.

- Each group of wind turbines has series impedance $Z_{1 \mathrm{p}}, Z_{2 \mathrm{p}}, Z_{3 \mathrm{p}}$

- Each branch has unique impedance and is connected to a group of wind turbines.

- Originally, each trunk circuit equivalent consisted of $n_{1}, n_{2}$ and $n_{3}$ turbines respectively

The output currents from each group are given as:

$\mathbf{I}_{1}=\mathrm{n}_{1} \mathbf{I}$

$\mathbf{I}_{2}=\mathrm{n}_{2} \mathbf{I}$

$\mathbf{I}_{\mathbf{3}}=\mathrm{n}_{3} \mathbf{I}$

The total output from the parallel branches are give as:

$\mathbf{I}_{\mathbf{T}}=\mathrm{n}_{1} \mathbf{I}+\mathrm{n}_{2} \mathbf{I}+\mathrm{n}_{3} \mathbf{I}$

$\mathbf{I}_{\mathbf{T}}=\left(\mathrm{n}_{1}+\mathrm{n}_{2}+\mathrm{n}_{3}\right) \mathbf{I}$
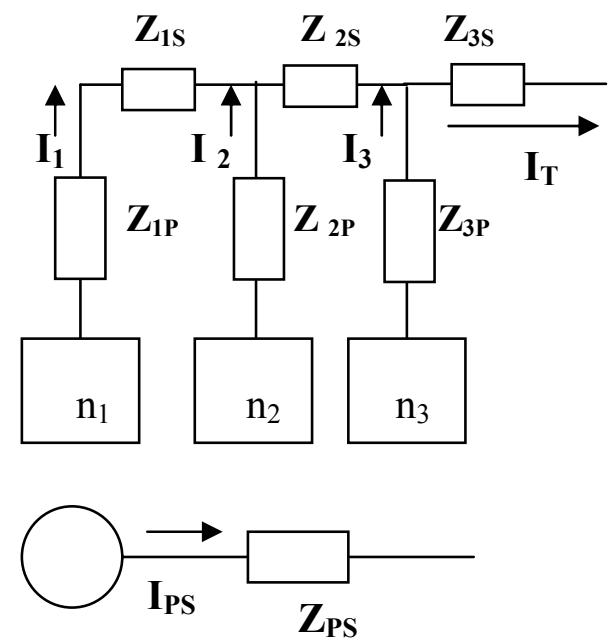

Figure 5. Parallel series connection of three groups of turbines.
The voltage drop across the impedances can be computed:

$$
\begin{aligned}
& \Delta \mathbf{V}_{\mathrm{Z1P}}=\mathbf{I}_{1} \mathbf{Z}_{1 \mathrm{P}}=\mathrm{n}_{1} \mathbf{I} \mathbf{Z}_{1 \mathrm{P}} \\
& \Delta \mathbf{V}_{\mathrm{Z1S}}=\mathbf{I}_{1} \mathbf{Z}_{1 \mathrm{~S}}=\mathrm{n}_{1} \mathbf{I} \mathbf{Z}_{1 \mathrm{~S}} \\
& \Delta \mathbf{V}_{\mathrm{Z2P}}=\mathbf{I}_{2} \mathbf{Z}_{2 \mathrm{P}}=\mathrm{n}_{2} \mathbf{I} \mathbf{Z}_{2 \mathrm{P}} \\
& \Delta \mathbf{V}_{\mathrm{Z2S}}=\left(\mathbf{I}_{1}+\mathbf{I}_{2}\right) \mathbf{Z}_{2 \mathrm{~S}}=\left(\mathrm{n}_{1} \mathbf{I}+\mathrm{n}_{2} \mathbf{I}\right) \mathbf{Z}_{2 \mathrm{~S}} \\
& \Delta \mathbf{V}_{\mathrm{Z3P}}=\mathbf{I}_{3} \mathbf{Z}_{3 \mathrm{P}} \\
& \Delta \mathbf{V}_{\mathrm{Z3S}}=\left(\mathbf{I}_{1}+\mathbf{I}_{2}+\mathbf{I}_{3}\right) \mathbf{Z}_{3 \mathrm{~S}}=\left(\mathrm{n}_{1} \mathbf{I}+\mathrm{n}_{2} \mathbf{I}+\mathrm{n}_{3} \mathbf{I}\right) \mathbf{Z}_{3 \mathrm{~S}}
\end{aligned}
$$

Based on losses across each impedance, the impedance loss can be computed as:

$\mathbf{S}_{\text {Loss_Z }} \mathbf{Z}_{1 \mathbf{P}}=\Delta \mathbf{V}_{\mathrm{Z1P}} \mathbf{I}_{\mathbf{1}}{ }^{*}=\mathbf{I}_{\mathbf{1}} \mathbf{I}_{\mathbf{1}}{ }^{*} \mathbf{Z}_{\mathbf{1 P}}=\mathrm{n}_{1}{ }^{2} \mathrm{I}^{2} \mathbf{Z}_{\mathbf{1 P}}$

$\mathbf{S}_{\text {Loss_Z2P }}=\Delta \mathbf{V}_{\mathrm{ZZ2} P} \mathbf{I}_{2}{ }^{*}=\mathbf{I}_{2} \mathbf{I}_{2}{ }^{*} \mathbf{Z}_{2 \mathrm{P}}=\mathrm{n}_{2}{ }^{2} \mathrm{I}^{2} \mathbf{Z}_{2 \mathrm{P}}$

$\mathbf{S}_{\text {Loss_Z3P }}=\Delta \mathbf{V}_{\mathrm{Z3P}} \mathbf{I}_{\mathbf{3}}{ }^{*}=\mathbf{I}_{\mathbf{3}} \mathbf{I}_{3}{ }^{*} \mathbf{Z}_{3 \mathbf{P}}=\mathrm{n}_{3}{ }^{2} \mathrm{I}^{2} \mathbf{Z}_{3 \mathbf{P}}$

$\mathbf{S}_{\text {Loss_Z1S }}=\Delta \mathbf{V}_{\mathbf{Z 1 S}} \mathbf{I}_{1}{ }^{*}=\mathrm{n}_{1}{ }^{2} \mathbf{I} \mathbf{I}^{*} \mathbf{Z}_{\mathbf{1 S}}=\mathrm{n}_{1}{ }^{2} \mathrm{I}^{2} \mathbf{Z}_{\mathbf{1 S}}$

$\mathbf{S}_{\text {Loss_Z2S }}=\Delta \mathbf{V}_{\mathbf{Z 2 S}}\left(\mathbf{I}_{1}+\mathbf{I}_{2}\right)^{*}=\left(\mathrm{n}_{1}+\mathrm{n}_{2}\right)^{2} \mathrm{I}^{2} \mathbf{Z}_{2 \mathrm{~S}}$

$\mathbf{S}_{\text {Loss_ZZ3S }}=\Delta \mathbf{V}_{\mathbf{Z Z S}}\left(\mathbf{I}_{\mathbf{1}}+\mathbf{I}_{\mathbf{2}}+\mathbf{I}_{\mathbf{3}}\right)^{*}=\left(\mathrm{n}_{1}+\mathrm{n}_{2}+\mathrm{n}_{3}\right)^{2} \mathrm{I}^{2} \mathbf{Z}_{\mathbf{3 S}}$

The equivalent total loss can be computed as:

Total Loss $=\mathbf{S}_{\text {ZTLOSS }}=\mathrm{I}_{\mathrm{T}}^{2} \mathbf{Z}_{\mathbf{T}}$

By equating the total loss to the sum of the individual impedance loss, we can find the equivalent impedance in a series-parallel circuit as shown in Figure 5.

$$
\begin{aligned}
\mathrm{I}_{\mathrm{T}}^{2} \mathrm{Z}_{\mathrm{T}}= & \mathrm{I}^{2}\left[\left(\mathrm{n}_{1}{ }^{2} \mathrm{Z}_{1 \mathrm{P}}+\mathrm{n}_{2}{ }^{2} \mathrm{Z}_{2 \mathrm{P}}+\mathrm{n}_{3}{ }^{2} \mathrm{Z}_{3 \mathrm{P}}\right)+\right. \\
& \left(\mathrm{n}_{1}^{2} \mathrm{Z}_{1 \mathrm{~S}}+\left(\mathrm{n}_{1}+\mathrm{n}_{2}\right)^{2} \mathrm{Z}_{2 \mathrm{~S}}+\left(\mathrm{n}_{1}+\mathrm{n}_{2}+\mathrm{n}_{3}\right)^{2} \mathrm{Z}_{3 \mathrm{~S}}\right]
\end{aligned}
$$

$$
\begin{aligned}
\mathrm{Z}_{\mathrm{T}}= & \frac{1}{\left(\mathrm{n}_{1}+\mathrm{n}_{2}+\mathrm{n}_{3}\right)^{2}}\left[\left(\mathrm{n}_{1}^{2} \mathrm{Z}_{1 \mathrm{P}}+\mathrm{n}_{2}^{2} \mathrm{Z}_{2 \mathrm{P}}+\mathrm{n}_{3}^{2} \mathrm{Z}_{3 \mathrm{P}}\right)+\right. \\
& \left(\mathrm{n}_{1}^{2} \mathrm{Z}_{1 \mathrm{~S}}+\left(\mathrm{n}_{1}+\mathrm{n}_{2}\right)^{2} \mathrm{Z}_{2 \mathrm{~S}}+\left(\mathrm{n}_{1}+\mathrm{n}_{2}+\mathrm{n}_{3}\right)^{2} \mathrm{Z}_{3 \mathrm{~S}}\right]
\end{aligned}
$$$$
\mathrm{Z}_{\mathrm{T}}=\frac{\sum_{i=1}^{n p} n_{i}^{2} Z_{i P}+\sum_{i=1}^{n s}\left(\sum_{j=1}^{n s} n_{j}\right)^{2} Z_{i s}}{\left(\sum_{i=1}^{n p} n_{i}\right)^{2}}
$$

\section{E. Shunt representation}

Consider an equivalent circuit for the transmission line shown below. Because the nature of the capacitance generates reactive power that is proportional to the square of the voltage across them, and considering that the bus voltage is close to unity under normal conditions, the representation of the shunt $\mathrm{B}$ can be considered as the sum of all the shunts in the power systems network. This assumption is close to reality under normal condition. 


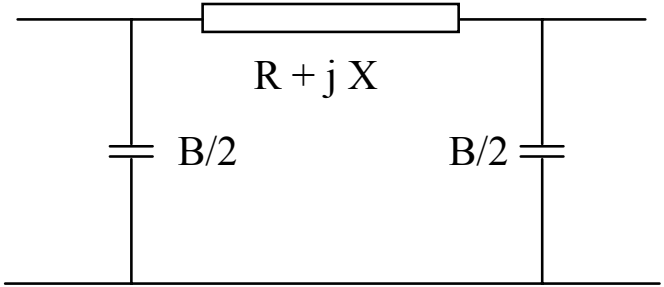

Figure 6. Representing the line capacitance within a wind farm.

With the assumption presented above, we can compute the total shunt capacitance within the wind power plant as follows:

$$
B_{t o t}=\sum_{i=1}^{n} B_{i}
$$

\section{F. Pad mount transformer representation}

The pad mount transformer must be represented to process the entire wind power plant. The equivalent circuit can be scaled so that the resulting voltage drop across the (leakage) impedances and the reactive and real power losses are equal to the sum of individual reactive and real losses of the turbines.
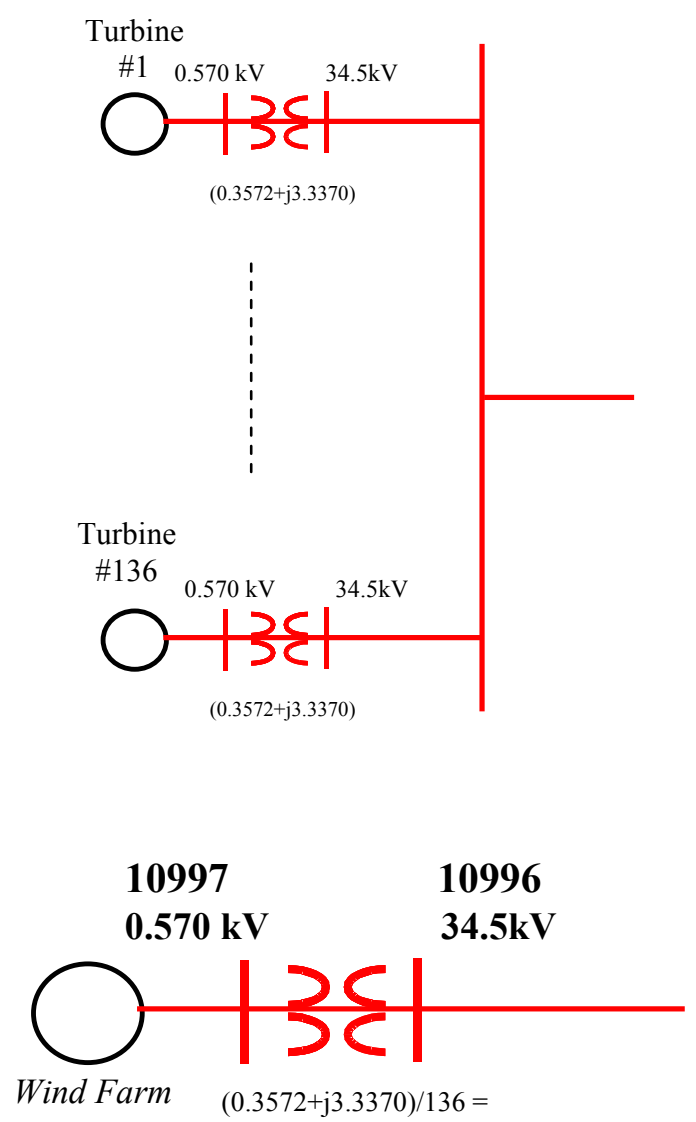

(136 turbines) ${ }^{(0.0026+\mathrm{j} 0.02454)}$

Figure 7. Pad mount representation within the wind farm.
The equivalent representation for the entire wind power plant can be computed as the impedance of a single transformer divided by the number of the turbines.

\section{$\mathbf{Z}_{\text {PMXFMR_WF }}=\mathbf{Z}_{\text {PMXFMR_WTG }} / \mathrm{n}_{\text {turbine }}$}

As an example, the pad-mount transformer impedance for the NMWEC is:

$Z_{\text {PMXFMR_WTG }}=(0.3572+$ j 3.3370) p.u.

The number of turbines is $n_{\text {turbine }}=136$ turbines.

Using the equation above, the equivalent impedance for the pad-mount transformer represented by a single turbine for the entire wind power plant is:

$\mathbf{Z}_{\text {PMXFMR_WF }}=\mathbf{Z}_{\text {PMXFMR_wTG }} / \mathrm{n}_{\text {turbine }}$

$Z_{\text {PMXFMR_WF }}=(0.0026+\mathbf{j 0 . 0 2 4 5 4 )})$.u.

\section{DifFERENT EQUiVALENCE CONFIGURATIONS}

\section{A. Equivalence of complete circuit (EOCC)}

We seek to find the equivalent collector impedance taking into account all conductors in the collector system. We will use the NMWEC collector system to illustrate the equivalencing methodology. The complete circuit representation for the NMWEC is illustrated in Figure 8. In this diagram, blocks D1 through D23 represent groups of turbines connected as a daisy-chain network (refer to Figure 2). Several daisy-chain networks are connected to nodes N1 through N8. Node N1 through node N8 are connected to bus 10998, the low-voltage side of the substation transformer. To derive the equivalent collection system parameters $(\mathrm{R}, \mathrm{X}$ and B in Fig. 1) for this collector system, the following procedure is suggested:

- Analyze each block of daisy chain connections (e.g. D1, D2 ... D23). Use the method described in Section II B to find the equivalent impedance if the collector subsystem represented by blocks D1, D2, D3, etc. As discussed in Section B below, one option is to ignore the impedance of the daisy-chain connection. This may be justifiable in location where the line section is very short.

- Several blocks are connected to a node (e.g. D1 through D5 are connected to node N1 and blocks D6 through D10 are connected to node N2). We can use the method described in section II D to find the equivalent impedance in this simplification. 


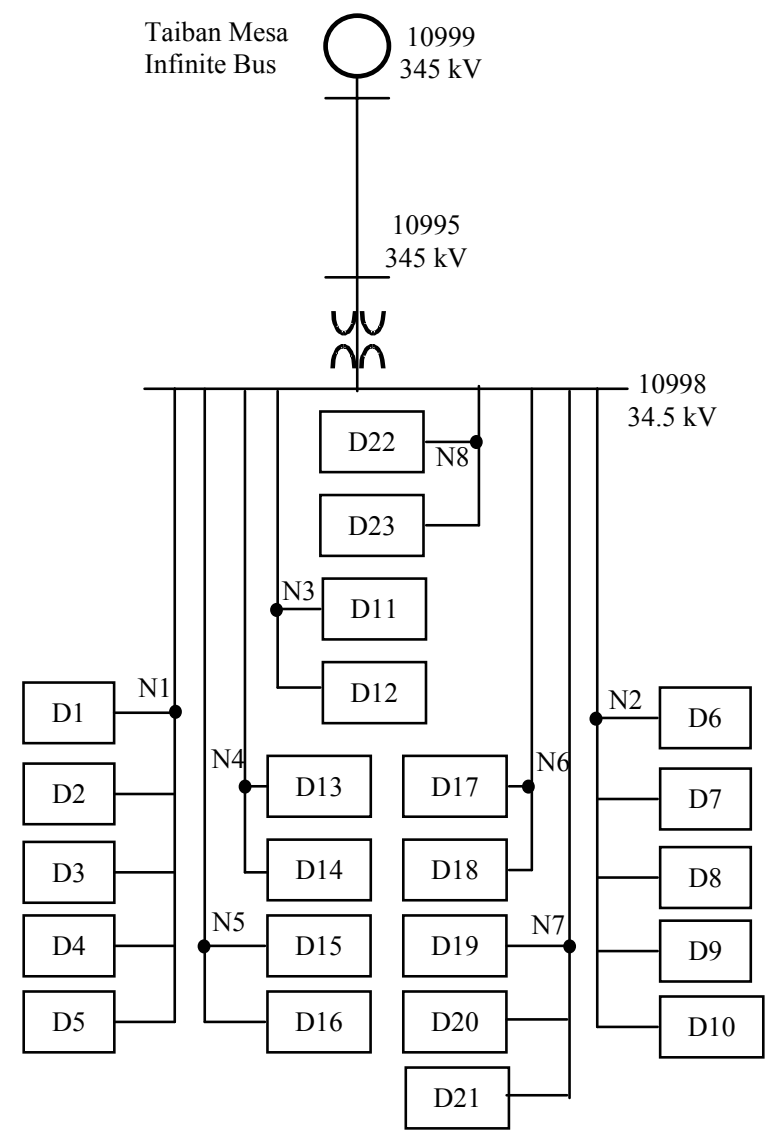

Figure 8. Complete collector system network in the wind farm.

- In some of the blocks, for example the blocks connected to Node 3 through Node 8, the block connections are computed by using the method described in section II B.

- The next step is to connect Nodes N1 through N8 to bus 10998 and find the equivalent impedance within the wind power plant. The method described in section II C is used to complete this task.

- The equivalent shunt capacitance, representing the capacitance of the cables and overhead lines, is then computed using the method described in section II E.

- Finally, we can compute the equivalent impedance of the pad mount transformer using the method described in section II F.

\section{B. Equivalence of major lines (EOML)}

This representation ignores the impedance in the daisy-chain connections. For example, in Figure 8, only connections from Node 1 through Node 8 are considered. The daisy-chain connections inside blocks D1 through D23 are ignored. The method described in section II $\mathrm{C}$ is used to solve this equivalent circuit

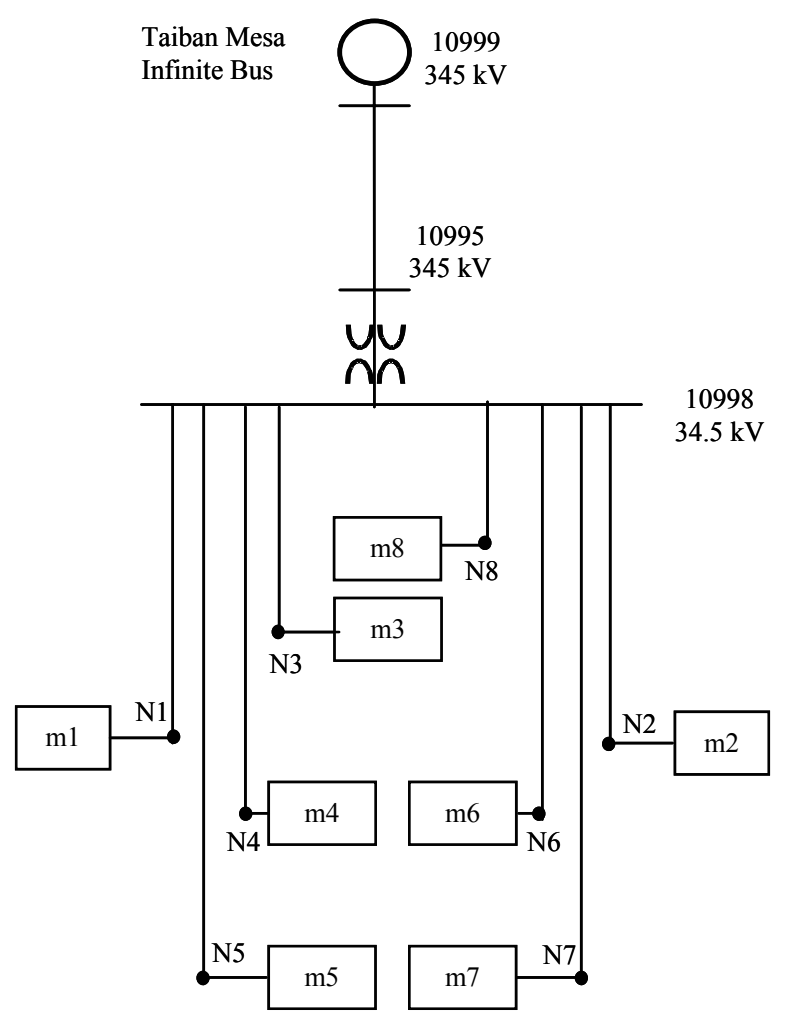

Figure 9. Major lines in the wind farm.

representation. The letters $\mathrm{m} 1$ through $\mathrm{m} 8$ indicate the number of turbines connected to node N1 through node N8.

The equivalent shunt capacitance representing the capacitance of the cables and overhead lines is computed using the method described in section II E. The equivalent impedance of the pad mounted transformer is computed using the method described in section II F.

\section{Comparison of different types of representations}

Table 1 compares the calculated results from different circuit representations and the equivalent impedances. The EOCC and EOML collector system

Table 1. Equivalent Circuit of Collector System

\begin{tabular}{|l|l|l|c|}
\hline \multirow{2}{*}{$\begin{array}{l}\text { Circuit } \\
\text { Representation }\end{array}$} & \multicolumn{3}{|c|}{ Impedance-Shunt Admittance } \\
\cline { 2 - 4 } & \multicolumn{1}{|c|}{$\mathbf{R}$} & \multicolumn{1}{|c|}{ X } & B \\
\hline EOCC & 0.01345 & 0.0497 & 0.1004 \\
\hline EOML & 0.008973 & 0.03527 & 0.0605 \\
\hline PNM & 0.0107 & 0.0214 & 0.0699 \\
\hline
\end{tabular}

Table 2. Other Impedances

\begin{tabular}{|l|c|c|c|}
\hline & From - To & R & X \\
\hline $\begin{array}{l}\text { HV Line } \\
\text { 345 KV }\end{array}$ & $\mathbf{1 0 9 9 5 - 1 0 9 9 9}$ & 0.002 & 0.002 \\
\hline $\begin{array}{l}\mathbf{3 4 . 5 k V / 3 4 5 k V} \\
\text { Transformer }\end{array}$ & $\mathbf{1 0 9 9 8 - 1 0 9 9 5}$ & 0.0014 & 0.0828 \\
\hline $\begin{array}{l}\text { WTG } \\
\text { Transformer }\end{array}$ & $\mathbf{0 . 5 7 k V / 3 4 . 5 k V}$ & 0.0026 & 0.0245 \\
\hline
\end{tabular}


impedance for the wind power plant are calculated using the methods described above. As expected, the "major lines" representation has a smaller impedance value and a smaller shunt representation value compared to the "complete circuit" equivalent impedance. The EOML has a lower resistance but a higher inductance than the equivalent impedance that Public Service of New Mexico has been using. From Table 1, we can conclude that the resulting equivalent impedance is lower if we do not include the trunk circuits. For example the resistive $\mathrm{R}$ is lower by $33 \%$, the inductive part $\mathrm{X}$ is lower by $30 \%$, and the capacitance is lower by $40 \%$. The last row (labeled PNM) of Table 1 is based on previously calculated impedance. The resistance $\mathrm{R}$ is calculated from real power losses and $\mathrm{X}$ is calculated by estimating $\mathrm{X} / \mathrm{R}$ ratio of the collector system in the wind power plant and $\mathrm{B}$ values is estimated by adding the individual Bs. The impedance value of the pad-mount (WTG) transformer represents the impedance of the equivalent transformer for 136 turbines. The equivalent pad-mount transformer can be computed as shown in Table 2.

This approach for calculating $\mathrm{X}, \mathrm{R}$ and $\mathrm{B}$ using EOCC suggested by the authors has been adopted by the wind developer for estimating equivalent impedances of proposed wind power plants for interconnection study purposes.

\section{LOAD FLOW ANALYSIS}

\section{A. Power flow comparison}

To validate the results of the calculation for equivalencing the collector systems using the method presented in section III, we use a load flow analysis. We modeled the complete circuit in the PSLF program, which consists of 136 turbines. All the impedances in the collector systems were entered in the load-flow model. We also modeled the equivalent representations derived using the EOCC and EOML methods described above to facilitate computation of losses with the load flow program for comparison purposes. To approximate the performance at the point of interconnection it is important to account for the losses in the collector system. The resulting apparent power MVA and the current flows in the branches are tabulated in Table 3. Table 3 shows the three types of representations. Note, that the current flowing in the line segment or transformers is based on the actual values (i.e. it is not in per unit values). There is a significant difference in the scaling because of the different voltage levels. The low

Table 3. MVA and Amps Comparison

\begin{tabular}{|c|c|c|c|c|c|c|c|c|}
\hline \multirow{2}{*}{\begin{tabular}{|l} 
Full Load \\
Current Flow
\end{tabular}} & \multirow{2}{*}{\begin{tabular}{|l} 
From \\
Bus
\end{tabular}} & \multirow{2}{*}{\begin{tabular}{|l|} 
To \\
Bus \\
\end{tabular}} & \multicolumn{2}{|c|}{ Complete (136WTG) } & \multicolumn{2}{|c|}{ EO CC } & \multicolumn{2}{|c|}{ EO ML } \\
\hline & & & MVA & AMPS & $\overline{M V A}$ & AMPS & $\overline{M V A}$ & AMPS \\
\hline HV Line 345kV & 10995 & 10999 & 199.5 & 317 & 210.5 & 335.5 & 212.2 & 338.2 \\
\hline HV Transformers & 10995 & 10998 & 199.5 & 317 & 210.9 & 335.5 & 212.6 & 338.2 \\
\hline Dist. Lines (WF) & 10998 & 10996 & 202.7 & 3328.7 & 200.5 & 3354.6 & 202.1 & 3382.5 \\
\hline WTG Transfomers & 10996 & 10997 & 204 & 3323 & 203.5 & 3393 & 203.8 & 3405.8 \\
\hline & & & & & & & & \\
\hline
\end{tabular}

Table 4. Losses Comparison (in MW and MVAR)

\begin{tabular}{|c|c|c|c|c|c|c|c|c|}
\hline Full Load & From & To & Complete & (136WTG) & EO & CC & EO & $M L$ \\
\hline Losses Comparison & Bus & Bus & Ploss & Qloss & Ploss & Qloss & Ploss & Qloss \\
\hline HV Line 345kV & 10995 & 10999 & 0.72 & 0.72 & 0.8 & 0.8 & 0.82 & 0.82 \\
\hline HV Transformers & 10995 & 10998 & 0.57 & 32.75 & 0.56 & 33.27 & 0.57 & 33.83 \\
\hline Dist. Lines (WF) & 10998 & 10996 & 4.13 & 5.33 & 5.48 & 10.17 & 3.69 & 8.46 \\
\hline WTG Transfomers & 10996 & 10997 & 1.36 & 9.52 & 1.07 & 10.07 & 1.08 & 10.15 \\
\hline
\end{tabular}

Table 5. Collector System Losses

\begin{tabular}{|c|c|c|c|c|}
\hline Losses & \multicolumn{2}{|c|}{ Complete (136WTG) } & EOCC & EOML \\
\hline Ploss & $4.13 \mathrm{MW}$ & $2.02 \%$ & $2.69 \%$ & $1.81 \%$ \\
\hline Qloss & $5.33 \mathrm{MVAR}$ & $2.61 \%$ & $4.99 \%$ & $4.15 \%$ \\
\hline
\end{tabular}

Table 6. Distributed Line Impedance $Z$ (p.u.), B, X/R and B/R Calculated from Losses

\begin{tabular}{|c|c|c|c|c|}
\hline $\begin{array}{c}\text { Equir. } \\
\text { Rep. }\end{array}$ & Zdistlines & B & X/R & B/R \\
\hline Compl & $(0.0104+j 0.0388)$ & 0.1004 & 3.7 & 9.7 \\
\hline EOCC & $(0.0136+j 0.0503)$ & 0.1004 & 3.7 & 7.4 \\
\hline EOML & $(0.009+j 0.0355)$ & 0.0605 & 3.9 & 6.7 \\
\hline PNM & $(0.0107+j 0.0214)$ & 0.0699 & 2 & 5.7 \\
\hline
\end{tabular}


voltage at the wind turbine (570 volt), the medium voltage $(34.5 \mathrm{kV})$ between the high side of the pad mount transformer and the low side of substation transformer, and high voltage $(345 \mathrm{kV})$ after the high side of the substation transformer.

The power loss shown in Table 4 is based on the load-flow calculation. The real power loss is caused by the resistive part of the impedance. The reactive power loss is the balance of reactive power absorbed by the line inductance and the reactive power injected by the susceptance of the lines. In the load-flow calculation, only the total reactive power loss is listed, the two components of VAR sources are not separated. The real power loss is the largest in the collector system. In the full circuit representation (136 turbines), the real power loss is computed as the sum of the collector system losses. The real and reactive losses in the collector system in the wind power plant are tabulated in Table 5. As shown in Table 5, both the EOCC and the EOML give a very good approximation of the real power loss. The reactive power losses in the collector system, both EOCC and EOML, have larger values than the complete representation of 136 wind turbines installed in the wind power plant. This is a result of the conservative assumption that the output currents from all turbines are equal in magnitude and in phase angle.

\section{B. Impedance calculated from losses}

From section IV A, we tabulated the results from the load flow analysis and then, we can compute the impedance from the calculated losses and calculated branch currents. In this section (section IV B), we are trying to estimate the equivalent impedance by looking at collector system internal losses using the complete system (136 turbines). From Tables 3 and 4, the real and reactive components of the impedance can be retraced to check the load-flow calculation. The resistive part of the impedance can be calculated from the real power loss and the current flow.

$R_{p u}=\frac{P_{\text {Loss }}}{3 I^{2} Z_{\text {base }}}$

where, the $Z_{\text {base }}$ is the base impedance calculated on 100 MVA system base.

$Z_{\text {base }}=\frac{V_{\text {LL_base }}^{2}}{S_{\text {base }}}$

The inductance can be calculated from the reactive power loss. Here, the reactive power caused by the inductance in the lines must be extracted from the total reactive power calculated by load flow. The total reactive power minus the reactive power generated by the shunt capacitance $\left(\mathrm{B}_{\mathrm{pu}}\right)$ is the reactive power generated by the inductance in the impedance. Note that the $\mathrm{B}_{\mathrm{pu}}$ was calculated previously during the circuit reduction and is listed in Table I.

$$
X_{p u}=\frac{Q_{\text {tot_Loss }_{\text {L }}}-V_{p u}^{2} B_{p u} S_{\text {base }}}{3 I^{2} Z_{\text {base }}}
$$

The equivalent impedance was calculated and tabulated in Table 6 based on the equations above.

Based on the result of this study, the authors recommendation is that New Mexico Energy Center be modeled with the following collector system impedances:

a) pad mounted step-up transformer impedance $\mathrm{Rxfm}+\mathrm{j}$ Xxfm $=(0.0026+\mathrm{j} 0.0245)$ p.u.,

b) collector system impedance: $R+j X=0.0104+j$ 0.0388 p.u. with $\mathrm{B}=0.1004$ p.u.

Notice that $\mathrm{X}$ and $\mathrm{B}$ values for the collector system impedance are appreciably higher than the ones initially supplied by PNM.

In the process of designing a collector system, an estimation of total real power losses (excluding pad mounted transformers) is often available. At full load, losses may range from $1.5 \%$ 6o $3 \%$. It is possible to estimate the equivalent impedance by looking at collector system from the internal real losses.

The inductance can be estimated by assuming a suitable $\mathrm{X} / \mathrm{R}$ and $\mathrm{B} / \mathrm{R}$ ratios. Typical $\mathrm{X} / \mathrm{R}$ ratio for collector systems may range from 6 to 10 , depending on the relative amount of underground and overhead lines. For the NMWEC, for example, for the NMWC, $\mathrm{X} / \mathrm{R}$ is approximately 3.8 , from which $\mathrm{X}$ can then be estimated. As stated before, susceptance can be computed directly as shown in Section IIE.

\section{CONCLUSION}

This paper describes methods used to develop an equivalence of a collector system in a large wind power plant. We derived equations to find the equivalent circuits for three different network configurations using simple electric circuit theory with the results shown in Table 1. These calculations allow rigorous computation of equivalent collector system impedance for virtually any collector system size and configuration. We also used load flow to verify the results of the equivalencing methodology. By using the losses in the collector system, we can compute the equivalent impedances and admittances as shown in Table 6.

The ratio of $\mathrm{X} / \mathrm{R}$ is very consistent for the EOCC, EOML and Complete representation. While the ratio $\mathrm{B} / \mathrm{R}$ for EOCC and EOML is very consistent, the value of $\mathrm{B} / \mathrm{R}$ for complete equivalent circuit is over predicted. It is also shown that the data from PNM for $\mathrm{X} / \mathrm{R}$ and $\mathrm{B} / \mathrm{R}$ are under predicted compared to the other calculations. 
Very large and diverse wind power plants can be represented by dividing the large wind power plant into smaller groups of wind turbines with similar attributes. The method described in this paper is intended to help utility planners get a quick and simple calculation for predicting the losses and behavior of the planned wind power plant with a good level of confidence.

This methodology has a practical application. This approach for calculating X, R, and B using EOCC was tested and validated by the authors and has been adopted by the wind developer for estimating equivalent impedance of proposed wind power plants for interconnection study purposes. Recommendations were provided to PNM to adjust the equivalent circuit representation for this project.

Rather than estimating the impedance by visual inspection as initially used, much more accurate result can be obtained by taking into account the number of wind turbine generators that are injecting currents into each branch.

One thing that we did not have to time to incorporate in this study is assessing the $\mathrm{Q}_{\max }$ and $\mathrm{Q}_{\min }$ capability of the wind power plant. This reactive power capability is an important aspect of the wind power plant that will be continued in the future investigation.

\section{ACKNOWLEDGMENT}

We acknowledge the support of the U.S. Department of Energy, Public Service Company of New Mexico, FPL Energy, General Electric and Utility Wind Interest Group (UWIG). We also thank William Price from General Electric International Inc., for help and discussions during the development of this project.

\section{REFERENCES}

[1] Zavadil, R.; Miller, N.; Ellis, A.; Muljadi, E. "Making Connections," Power and Energy Magazine, IEEE, Vol. 3, Issue 6, Nov.-Dec. 2005, pp. 26-37.

[2] Zavadil, R.M.; Smith, J.C. "Status of Wind-Related U.S. National and Regional Grid Code Activities," Power Engineering Society General Meeting, June 12-16, 2005, pp. 2892-2895.

[3] Miller, N.W.; Sanchez-Gasca, J.J.; Price, W.W.; Delmerico, R.W. "Dynamic Modeling of GE 1.5 and 3.6 MW Wind Turbine-Generators for Stability Simulations," Power Engineering Society General Meeting, IEEE, Vol. 3, July 13-17, 2003, pp. 1977-1983.

[4] Miller, A.; Muljadi, E.; Zinger, D. "A Variable-Speed Wind Turbine Power Control," IEEE Transactions on Energy Conversion, Vol. 12., No. 2, June 1997 pp. 181-186.

[5] Kersting, W.H. Distribution System Modeling and Analysis, CRC Press, Boca Raton, FL, 2001. 


\section{REPORT DOCUMENTATION PAGE}

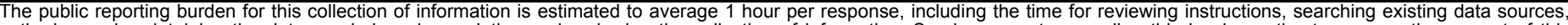

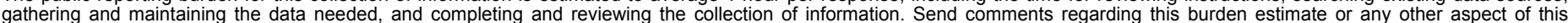

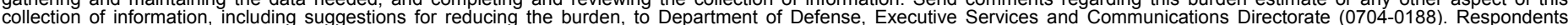

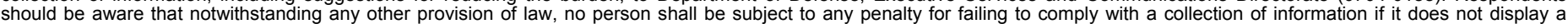

should be aware that noth

PLEASE DO NOT RETURN YOUR FORM TO THE ABOVE ORGANIZATION.

\begin{tabular}{l|l|l|l} 
1. REPORT DATE $(D D-M M-Y Y Y Y)$ & 2. & REPORT TYPE & 3. DATES COVERED (FrOm - TO)
\end{tabular} January 2006

Conference paper

4. TITLE AND SUBTITLE

Equivalencing the Collector System of a Large Wind Power Plant: Preprint 5a. CONTRACT NUMBER

DE-AC36-99-G010337

5b. GRANT NUMBER

5c. PROGRAM ELEMENT NUMBER

5d. PROJECT NUMBER

NREL/CP-500-38940

5e. TASK NUMBER

WER6.2112

5f. WORK UNIT NUMBER
7. PERFORMING ORGANIZATION NAME(S) AND ADDRESS(ES)

National Renewable Energy Laboratory

1617 Cole Blvd.

Golden, CO 80401-3393
8. PERFORMING ORGANIZATION REPORT NUMBER

NREL/CP-500-38940

9. SPONSORING/MONITORING AGENCY NAME(S) AND ADDRESS(ES)

10. SPONSOR/MONITOR'S ACRONYM(S) NREL

11. SPONSORING/MONITORING AGENCY REPORT NUMBER

12. DISTRIBUTION AVAILABILITY STATEMENT

National Technical Information Service

U.S. Department of Commerce

5285 Port Royal Road

Springfield, VA 22161

13. SUPPLEMENTARY NOTES

14. ABSTRACT (Maximum 200 Words)

This paper focuses on our effort to develop an equivalent representation of a wind power plant collector system for power system planning studies..

\section{SUBJECT TERMS}

wind turbine; wind farm; wind power plant; wind energy; aggregation; equivalence; distribution network; collector system; power systems; renewable energy

\begin{tabular}{|c|c|c|c|c|}
\hline \multicolumn{3}{|c|}{ 16. SECURITY CLASSIFICATION OF: } & \multirow{2}{*}{$\begin{array}{l}\text { 17. LIMITATION } \\
\text { OF ABSTRACT } \\
\text { UL }\end{array}$} & \multirow{2}{*}{$\begin{array}{ll}\text { 18. } & \text { NUMBER } \\
\text { OF PAGES }\end{array}$} \\
\hline $\begin{array}{l}\text { a. REPORT } \\
\text { Unclassified }\end{array}$ & $\begin{array}{l}\text { b. ABSTRACT } \\
\text { Unclassified }\end{array}$ & $\begin{array}{l}\text { c. THIS PAGE } \\
\text { Unclassified }\end{array}$ & & \\
\hline
\end{tabular}

19a. NAME OF RESPONSIBLE PERSON

19b. TELEPHONE NUMBER (Include area code) 